\title{
Electroporation of Postimplantation Mouse Embryos In Utero
}

\author{
Cheng-Chiu Huang and Abel Carcagno
}

Gene transfer by electroporation is possible in mouse fetuses within the uterus. As described in this protocol, the pregnant female is anesthetized, the abdominal cavity is opened, and the uterus with the fetuses is exteriorized. A solution of plasmid DNA is injected through the uterine wall directly into the fetus, typically into a cavity like the brain ventricle, guided by fiber optic illumination. Electrodes are positioned on the uterus around the region of the fetus that was injected, and electrical pulses are delivered. The uterus is returned to the abdominal cavity, the body wall is sutured closed, and the female is allowed to recover. The manipulated fetuses can then be collected and analyzed at various times after the electroporation. This method allows experimental access to later-stage developing mouse embryos.

\section{MATERIALS}

It is essential that you consult the appropriate Material Safety Data Sheets and your institution's Environmental Health and Safety Office for proper handling of equipment and hazardous materials used in this protocol.

RECIPES: Please see the end of this protocol for recipes indicated by $<R>$. Additional recipes can be found online at http://cshprotocols.cshlp.org/site/recipes.

Reagents

Analgesic

Anesthetic

Ketamine/xylazine mixture, isoflurane, and Avertin have been used successfully.

Betadine

EndoFree Plasmid Kit (QIAGEN)

Ethanol (70\%)

Fast Green (Sigma-Aldrich F7258)

Phosphate-buffered saline (PBS) $<\mathrm{R}>$ without $\mathrm{Ca}^{2+}$ and $\mathrm{Mg}^{2+}$ (warmed to $37^{\circ} \mathrm{C}$ )

Purified DNA solution of expression vectors

Expression vectors available for mammalian cells can also be used for embryo electroporation. The vector driven by the CMV/chick $\beta$-actin hybrid (CAG) promoter (Saito and Nakatsuji 2001) and human elongation factor $1 \alpha$ (EF1 $\alpha$ ) are frequently used (Tabata and Nakajima 2001). Plasmid DNA must be very pure and free of contaminants. Dissolve the DNA in $1 \times$ TE $\left(10 \mathrm{~mm}\right.$ Tris- $\mathrm{HCl}$ at $\mathrm{pH} 8.0$ with $1 \mathrm{~mm}$ EDTA) or $d d \mathrm{H}_{2} \mathrm{O}$ on the day of the experiment or the day before (if it is highly concentrated), and adjust to its final concentration (up to $5.0 \mathrm{mg} / \mathrm{mL}$, depending on your purpose). Fast Green (0.01\% final concentration) can be added to facilitate solution visualization during the injection process.

Timed pregnant female mice $(12.5-16.5 \mathrm{~d}$ postcoitum $[\mathrm{dpc}])$

From the Manipulating the Mouse Embryo collection, edited by Richard Behringer, Marina Gertsenstein, Kristina Vintersten Nagy, and Andras Nagy.

(C) 2018 Cold Spring Harbor Laboratory Press

Cite this protocol as Cold Spring Harb Protoc; doi:10.1101/pdb.prot094060 
C. - C. Huang and A. Carcagno

\section{Equipment}

Capillaries, glass (100 mm long; o.d. $=1 \mathrm{~mm}$, i.d. $=0.5 \mathrm{~mm}$; BF100-50-10, Sutter Instrument $)$

Electroporator (Square Wave Electroporation System, ECM 830, BTX, Harvard Apparatus)

Fiber optic light source with dual gooseneck

Forceps, \#5

Forceps, ring-style

Mechanical pipette puller (e.g., Sutter P-97)

Mouth-controlled micropipettor

Operating board

Pasteur pipettes, sterile

Peristaltic pump to deliver warm saline

Surgical gauze

Surgical instruments

Tweezer electrodes (Model 520, $7 \mathrm{~mm}$ in diameter, or Model 522, $10 \mathrm{~mm}$ in diameter; BTX, Harvard Apparatus)

UV light

Warming pad, temperature controlled

\section{METHOD}

Preparation of Micropipettes

1. Pull glass capillary tubes with a micropipette puller to make injection pipettes (see Protocol: Making Injection Pipettes [Nagy et al. 2006]).

For the Sutter Instruments P-97: pressure 500; heat 300; pull 30; velocity 40; time 1. Adjust the puller settings according to the diameter and thickness of the capillary used.

2. Open the tip of the pulled micropipettes with \#5 forceps to the desired outer diameter and tip length.

3. Mark the tip of the micropipette with a water-resistant marker for visual guidance.

4. Sterilize the micropipettes under UV light for $30 \mathrm{~min}$.

\section{Electroporation of Mouse Embryos In Utero}

5. Anesthetize the pregnant female mouse.

6. Place the mouse ventral side up on an operating board with a piece of laboratory diaper underneath the animal. Adjust the position of the mouse using tape or rubber bands to restrain the limbs.

7. Clean the abdomen with $70 \%$ ethanol and Betadine.

8. Cover the abdomen with sterile surgical gauze soaked in $37^{\circ} \mathrm{C}$ PBS.

Keep the uterus wet at all times during the surgery, adding warm saline to the sterile gauze as needed with a sterile Pasteur pipette.

9. Make a midline incision $(3-4 \mathrm{~cm})$ of the skin and then the abdominal muscle.

10. Place the ring forceps onto the antimesometrial side of the uterus (to avoid touching the placenta and major blood vessels) at the gap between embryos.

11. Gently pull the uterus out of the body cavity, and place it on the warm saline-soaked gauze (Fig. 1A).

12. Use a fiber optic light source to illuminate the embryos through the uterine wall.

13. Adjust individual embryos with the ring forceps or fingers to the optimal position for ventricle injection. 

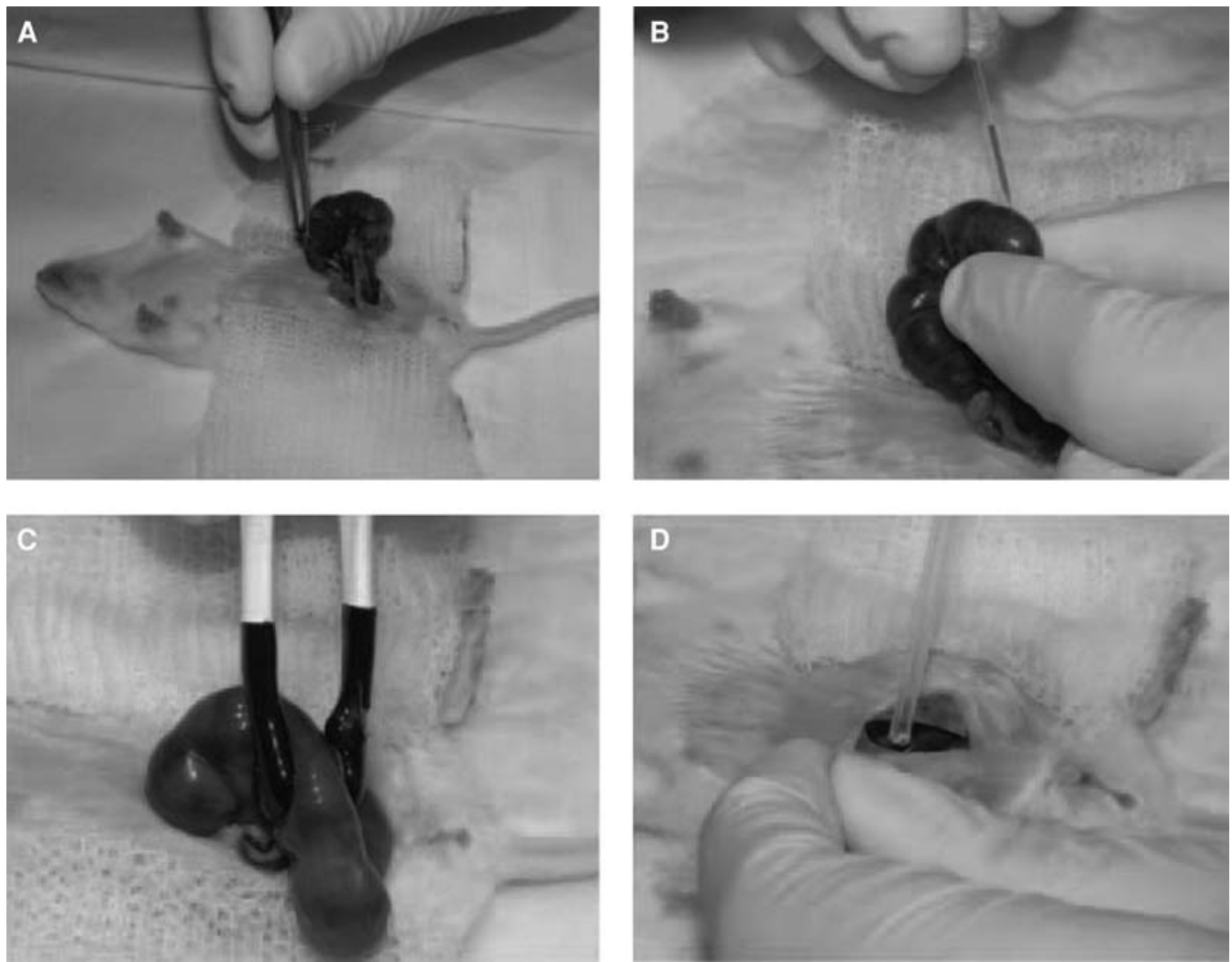

FIGURE 1. In utero electroporation of gene constructs. (A) Anesthetized pregnant female mouse with abdominal incision. The uterine horn with fetuses is gently pulled outside of the body. $(B)$ A fetus within the uterus is cradled by hand, and a DNA solution in a pulled glass capillary is injected into the brain ventricle. $(C)$ Electroporation paddles are placed on the uterus flanking the injected fetus, and electrical pulses are given. $(D)$ The uterus is placed back in the abdominal cavity.

14. Inject $1-2 \mu \mathrm{L}$ of DNA $(0.1-5 \mu \mathrm{g} / \mathrm{mL})$ solution into the lateral ventricle (for the cerebral cortex, cortical hem, or basal forebrain) or the fourth ventricle (for the cerebellum or spinal cord) with a mouth-controlled micropipette (Fig. 1B).

Before loading the injection pipette with the DNA solution, draw in $1 \mu \mathrm{L}$ and $2 \mu \mathrm{L}$ of water into the injection needle and use a marker to draw a line for these volumes.

15. Place the forceps electrodes onto the uterine wall at the position of the injected embryo. Apply five pulses ( $\sim 50 \mathrm{msec}, 30-50 \mathrm{~V})$ to the embryo at the desired angle.

Avoid holding, touching, or scratching the placenta or major blood vessels of the mesometrium with the forceps or electrodes (Fig. 1C).

16. Reposition the uterus back into the abdominal cavity (Fig. 1D).

17. Fill the abdominal cavity with warm saline.

18. Suture the abdominal muscle layer and then the skin.

19. Clean the sutured incision with $70 \%$ ethanol and Betadine.

20. Place the mouse on a temperature-controlled warming pad for recovery.

21. Give analgesic by a subcutaneous injection following local animal welfare guidelines.

\section{TROUBLESHOOTING}

Problem: There is a low rate of embryo survival after manipulation. 
C. - C. Huang and A. Carcagno

Solution: Consider the following:

- The total duration of the operation should not exceed $30 \mathrm{~min}$.

- Ensure that the uterus is kept warm and wet with warm saline during the whole procedure.

- Do not grab or pinch the placenta or major blood vessels of the uterus.

- Practice ventricle injections with the Fast Green dye first without electroporation.

- The amniotic fluid should not leak after injection. If this happens, modify the micropipette puller parameters, and adjust the outer diameter of the micropipette.

- Try not to place the electrodes close to the placenta or the heart of the embryo.

- Reduce the voltage pulse.

Problem: Transfection efficiency is low.

Solution: Consider the following:

- The DNA solution may not have been injected into the ventricle.

- Use only endotoxin-free DNA.

- Check plasmid quality by spectrophotometer and expression by cell culture transfection.

- During surgery, wet the electrodes with saline before applying electric pulses.

- Check cables on the electroporator for the generation of air bubbles when electric pulses are delivered into the saline solution.

- Increase the voltage pulse.

Phosphate-Buffered Saline (PBS)

Final

Amount to add

Reagent

(for $1 \times$ solution)

concentration

$(1 \times)$

$137 \mathrm{~mm}$

$2.7 \mathrm{mM}$

$10 \mathrm{~mm}$

$1.8 \mathrm{~mm}$
$0.2 \mathrm{~g}$

$1.44 \mathrm{~g}$

$0.24 \mathrm{~g}$
Final

concentration

Amount to add (for $10 \times$ stock)

$(10 \times)$

$1.37 \mathrm{M}$

$27 \mathrm{~mm}$

$100 \mathrm{~mm}$

$18 \mathrm{~mm}$

If necessary, $\mathrm{PBS}$ may be supplemented with the following:
$\mathrm{CaCl}_{2} \cdot 2 \mathrm{H}_{2} \mathrm{O}$
$0.133 \mathrm{~g}$
$1 \mathrm{~mm}$
$1.33 \mathrm{~g}$
$10 \mathrm{~mm}$
$\mathrm{MgCl}_{2} \cdot 6 \mathrm{H}_{2} \mathrm{O}$
$0.10 \mathrm{~g}$
$0.5 \mathrm{~mm}$
$1.0 \mathrm{~g}$
$5 \mathrm{~mm}$

PBS can be made as a $1 \times$ solution or as a $10 \times$ stock. To prepare $1 \mathrm{~L}$ of either $1 \times$ or $10 \times \mathrm{PBS}$, dissolve the reagents listed above in $800 \mathrm{~mL}$ of $\mathrm{H}_{2} \mathrm{O}$. Adjust the $\mathrm{pH}$ to 7.4 (or 7.2, if required) with $\mathrm{HCl}$, and then add $\mathrm{H}_{2} \mathrm{O}$ to $1 \mathrm{~L}$. Dispense the solution into aliquots and sterilize them by autoclaving for $20 \mathrm{~min}$ at $15 \mathrm{psi}\left(1.05 \mathrm{~kg} / \mathrm{cm}^{2}\right)$ on liquid cycle or by filter sterilization. Store PBS at room temperature.

\section{REFERENCES}

Nagy A, Gertsenstein M, Vintersten K, Behringer R. 2006. Making injection pipettes. Cold Spring Harb Protoc doi: 10.1101/pdb.prot4395.

Saito T, Nakatsuji N. 2001. Efficient gene transfer into the embryonic mouse brain using in vivo electroporation. Dev Biol 240: 237-246.
Tabata H, Nakajima K. 2001. Efficient in utero gene transfer system to the developing mouse brain using electroporation: Visualization of neuronal migration in the developing cortex. Neuroscience 103: 865-872. 


\section{Electroporation of Postimplantation Mouse Embryos In Utero}

Cheng-Chiu Huang and Abel Carcagno

Cold Spring Harb Protoc; doi: 10.1101/pdb.prot094060

\begin{tabular}{|c|c|}
\hline $\begin{array}{r}\text { Email Alerting } \\
\text { Service }\end{array}$ & Receive free email alerts when new articles cite this article - click here. \\
\hline $\begin{array}{l}\text { Subject } \\
\text { Categories }\end{array}$ & $\begin{array}{l}\text { Browse articles on similar topics from Cold Spring Harbor Protocols. } \\
\text { Developmental Biology (728 articles) } \\
\text { DNA Delivery/Gene Transfer ( } 344 \text { articles) } \\
\text { Mouse (437 articles) } \\
\text { Non-Viral Methods ( } 226 \text { articles) } \\
\text { Transgenic Mice (139 articles) }\end{array}$ \\
\hline
\end{tabular}

